\title{
Well Differentiated B3 Thymoma complicated with Vena Cava Superior Syndrome undergo Debulking and Chemotherapy
}

\author{
Wayan Wahyu Semaraputra ${ }^{1}$, Iin Noor Chozin ${ }^{1}$, Kenty Wantry $^{2}$, Artono Isharanto $^{3}$, Rachma \\ Dini Erawati ${ }^{4}$ \\ ${ }^{1}$ Pulmonology and Respiratory Department, Saiful Anwar Hospital, Universitas Brawijaya, Jaksa Agung Suprapto 2, Malang, 65112, Indonesia \\ ${ }^{2}$ Pathology Anatomy Department, Saiful Anwar Hospital, Universitas Brawijaya, Jaksa Agung Suprapto 2, Malang, 65112, Indonesia \\ ${ }^{3}$ Thoracic and Cardiovascular Surgery Department, Saiful Anwar Hospital, Universitas Brawijaya, Jaksa Agung Suprapto 2, Malang, 65112, Indonesia \\ ${ }^{4}$ Radiology Department, Saiful Anwar Hospital, Universitas Brawijaya, Jaksa Agung Suprapto 2, Malang, 65112, Indonesia \\ Abstract
}

Background: Thymoma is a rare neoplasm. This incident is comparable to 390 new cases reported per year. Genetic factors are believed to be one of the factors of B3 thymoma and thymus carcinoma. Multimodality of thymoma therapy (surgery, radiation and chemotherapy) gives better results.

Case Report: Mr A, 29 years old, with initial diagnosis of stage IV thymoma (according to Masaoka) with SVKS then undergo debulking, followed by chemotherapy with a regimen of Cisplatin + Vincristin, Cyclophospamid, Doxorubicin, Prednison every 21 days as much as 6 times. Subjective responses indicated by reduced complaints of chest pain and loss of swelling of the right arm. Semisubjective response indicated by increase of body weight. Objective response is progressive, so can be continued with second line chemotherapy or radiotherapy.

Conclusion: The prognosis of patient with well differentiated thymic carcinoma stadium iv (thymoma b3) complicated with vena cava superior syndrome was poor because of the objective response of the chemotherapy was progressive, and the relapse case was higher.

Keywords: chemotherapy, debulking, thymoma, VCSS

MRJ 2019; 2(1):56-61

\section{Introduction}

Thymoma represents a rare neoplasm. In the United States statistics from 2010 indicate an occurrence of $0.13 / 100,000$ cases per year. This occurrence contrasts with 390 reported new cases per year. Among men the incidence rate is the same as for women. ${ }^{1}$ There is no evidence about the etiology of the thymoma. Genetic factors are considered to be one of the thymoma and thymus carcinoma causes. The genetic factor was due to the loss of chromosome 6 and the segment damage of 13q. The changes that occur in the thymus carcinoma are chromosome 6 , segments $16 q, 3 p$ and 17p. Loss of chromosome 6 is believed to be one of the carcinogenesis factors of thymoma B3 and type C. ${ }^{2}$ Type B3 thymomas are associated with tumors that are composed mainly of round or polygonal epithelial cells and do not show atypia or only mild atypia. These tumors also contain minor components of lymphocytes and are displayed as growth sheets of neoplastic epithelial cells. They are considered equivalent to the thymic rich

\footnotetext{
*Corresponding author:

Wayan Wahyu Semara Putra (wayan.wahyu.semara.putra@gmail.com)

Pulmonology and Respiratory Department, Saiful Anwar Hospital - Universitas Brawijaya, Jaksa Agung Suprapto St. No. 2, Malang. 65112 , Indonesia
} 
epithelium in the traditional classification and the well-differentiated thymus carcinoma in the Kirchner and MullerHermelink classification. ${ }^{3}$ Management of thymoma depends on whether or not the tumor is invasive, staging and clinical patient. The therapy is surgical, but very rarely cases come in stage I or noninvasive so multimodality therapy such as surgery, radiation and chemotherapy give better results. ${ }^{4,5}$

\section{Background}

This interesting case was reported because of the poorly prognosis of Well Differentiated Thymic Carcinoma Stadium IV (Thymoma B3) complicated with Vena Cava Superior Syndrome. The multimodality diagnostic procedure and therapy need to be discussed with the multidiscipline team (MDT) to get the most suitable treatment for each patient.

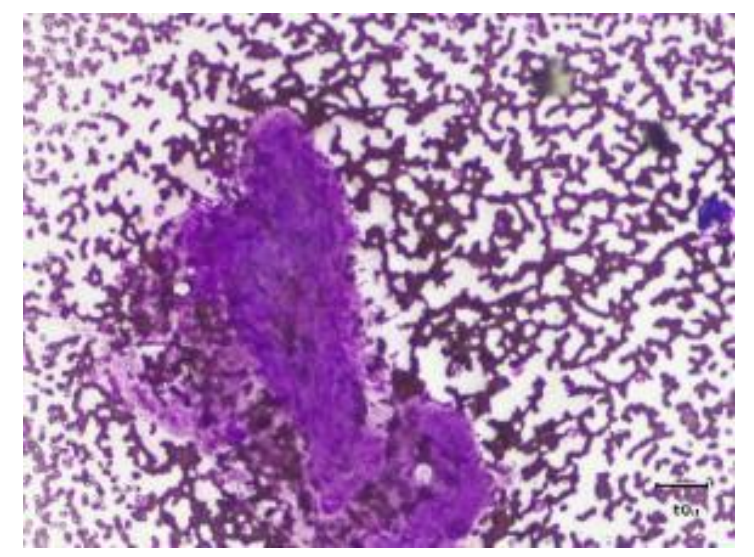
A

Figure 1. Histopathocogical examination of spescimen from transthoracic needle aspiration showed spindle mesenchymal tumor differentiate with spindle cell thymoma.

\section{Case}

A 29-year-old man complained of shortness of breath, right chest pain, and does not improve with rest. It was followed with swelling in the right arm. He was examined for complete blood count, chest X-Ray, and thoracic CT scan with contrast, transthoracic needle aspiration with ultrasound guiding, and EMG. The laboratory findings showed anemia. Thoracic CT Scan with contras showed anterior mediastinal mass that attached to the thoracic wall and encase great vascular, multiple lymphadenopathy suspected as lymphoma with differential diagnosed thymoma. The patient was performed a transthoracic needle aspiration with ultrasound guiding, and the cytology result showed as spindle cell thymoma with differential diagnosis ancient schwannoma. (Figure 1).

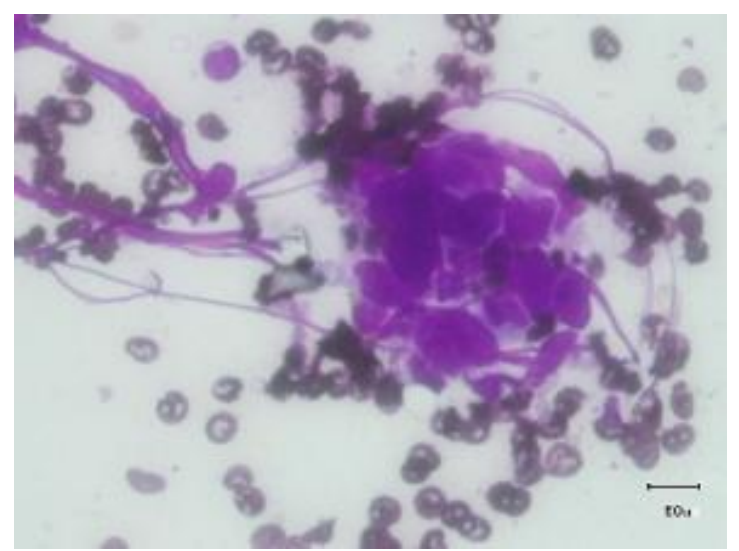

B 
Patient was concluded to have thymoma stadium IVa (Masaoka Staging) with VCSS as complication. The EMG and Harvey Masland Test (Repetitive Nerve Stimulation) didn't show a myasthenia gravis sign. The management of thymoma. stadium IVA is debulking surgery, chemotherapy and radiotherapy. Debulking surgery was planned with elective surgery with median sternotomy technique in the Saiful Anwar Hospital, Malang, Indonesia. It's been reported
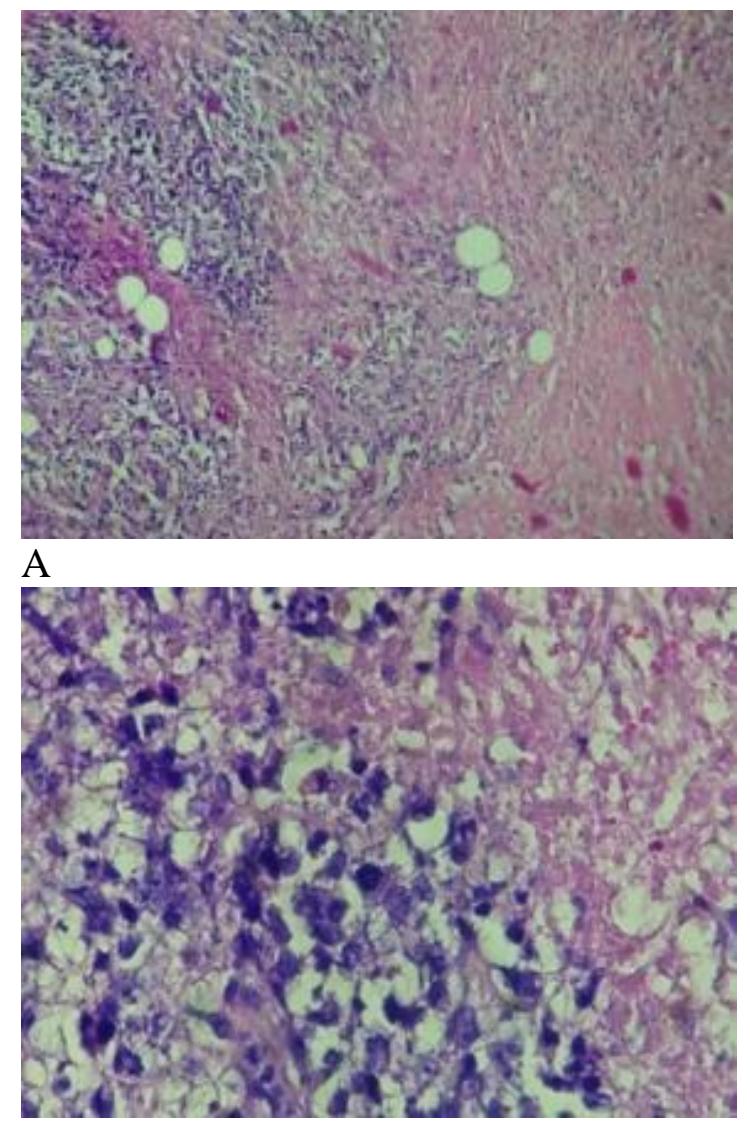
C

Figure 2. Histopatological examination revealed a well differentiated thymic carcinoma from Vries Coupe represent Thymoma B3 (A\&B) and from Debulking Surgery (C\&D) that a 29 years old male with initial diagnosis anterior mediastinal mass with anemia and VCSS. Patient underwent debulking surgery then continue with histopathology examination from the tumor (Fig. 2). The result of the histophatology was thymoma B3. The management after operation was chemotherapy with Cisplatin, Cyclophosphamide, Doxorubicin, Vincristine, Prednisone every 21 days, 6 cycles.
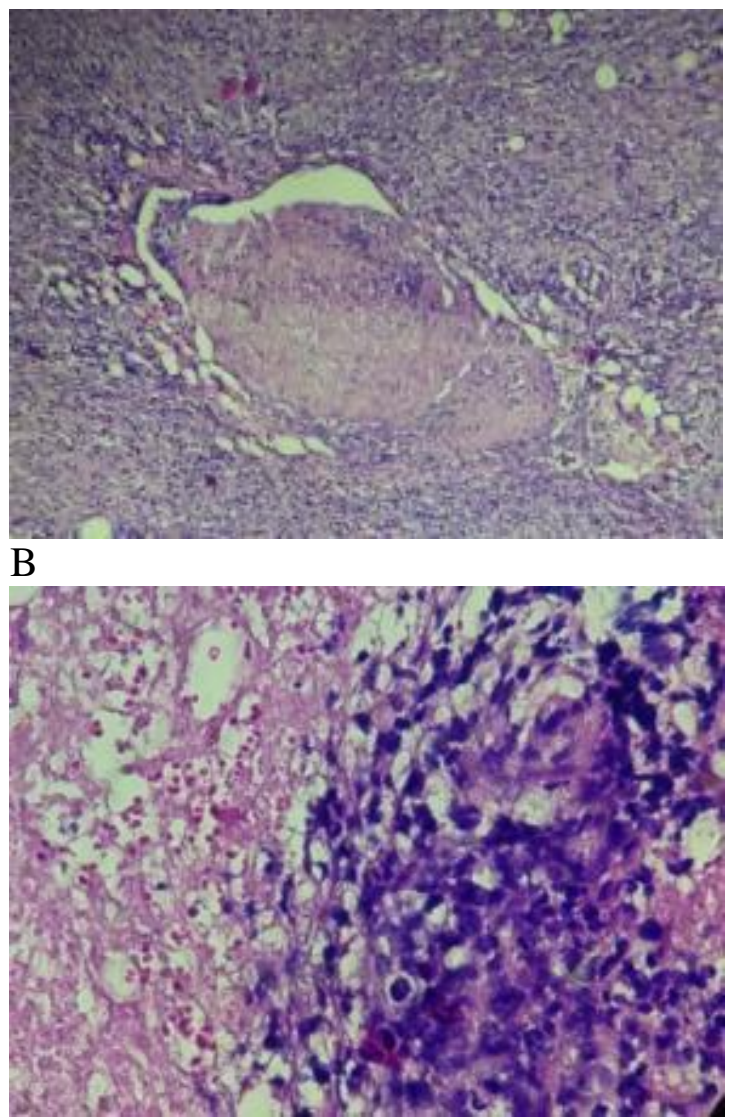

D 
The objective response was progressive disease from the radiologic findings (Fig 3 and Fig 4), so that the chemotherapy will be continued to the second line chemotherapy with radiotherapy.
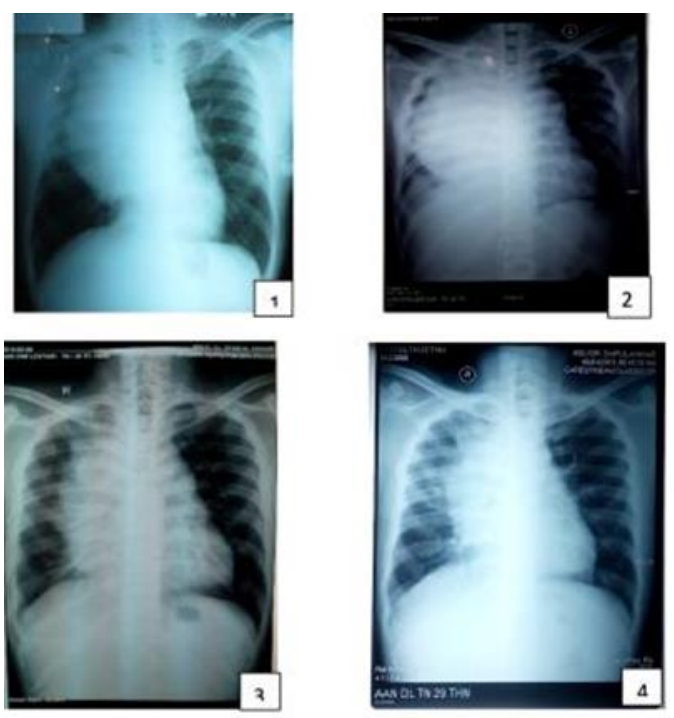

Figure 3. Chest X-Rays Evaluation: (3.1) Intial. (3.2) After Debulking Surgery. After $3^{\text {rd }}$ and $6^{\text {th }}$ Chemotherapy $(3.3 \& 3.4$ respectively).

\section{Discussion}

Almost $30 \%$ of thymoma has no typical symptoms, neither the physical examinations. The abnormality in the physical examination was correlated with the size of the tumor, the location and the interference that was caused by the tumor. The specific sign that lead to thymoma if there was a prejudice of a myasthenia gravis. ${ }^{5}$ Thymoma type B3 is composed with epithelial cell that rounded or polygonal and less or none of atypia. The component of the tumor has minor lymphosit and showed layers growth of neoplastic epithelial cells. ${ }^{3}$ Thymoma is a rare case, so the experience or the report of the thymoma chemotherapy was only published in a case report, retrospective review, or small prospective trial. According to some case reports, the cisplatin-based chemotherapy and combination chemotherapy are more superior than single chemotherapy. Some combination chemotherapy showed good response rate above $50 \%$. The regiment with CHOP is one of the protocol of thymoma chemotherapy. ${ }^{6}$ According to Masaoka, the successful of chemptherapy $92,6 \%$ for the $1^{\text {st }}$ stage. $85,7 \%$ for the $2^{\text {nd }}$ stage, $69,6 \%$ for the $3^{\text {rd }}$ stage, and $50 \%$ for the $4^{\text {th }}$ stage. $^{5}$ The relapse case after the radical resection was depend on the stage of the tumor, the size of the tumor, and the type of the tumor. ${ }^{7}$ The prognosis is based on the Masaoka classification is less accurate in this thymoma B3 case pr thymic carcinoma. ${ }^{8}$ 
A

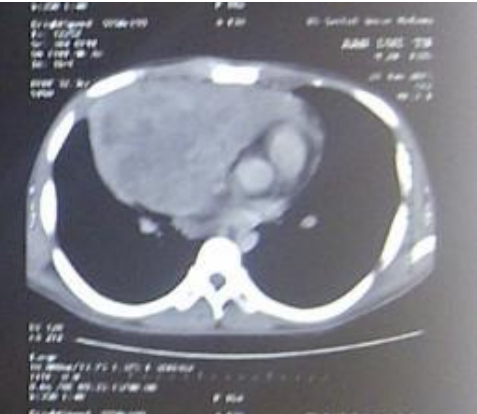

Axial

B

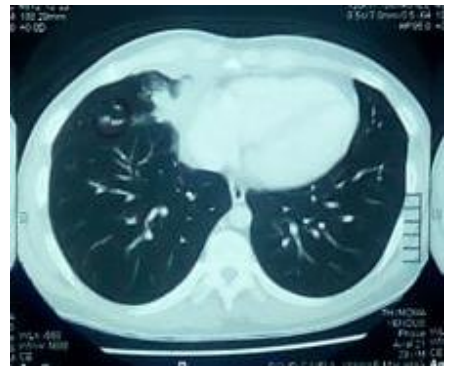

Axial

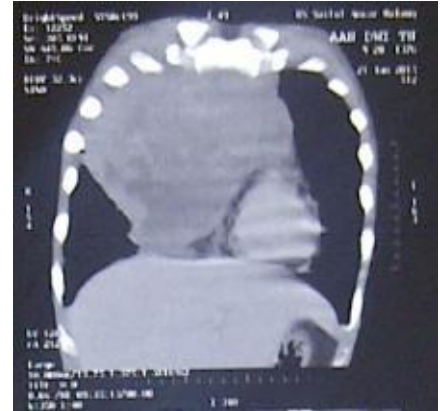

Coronal

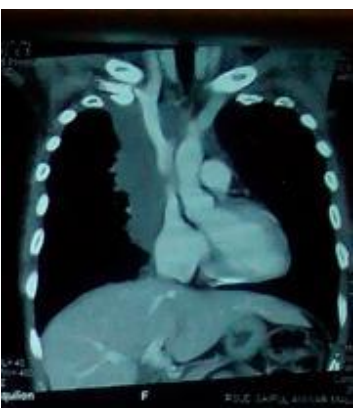

Coronal

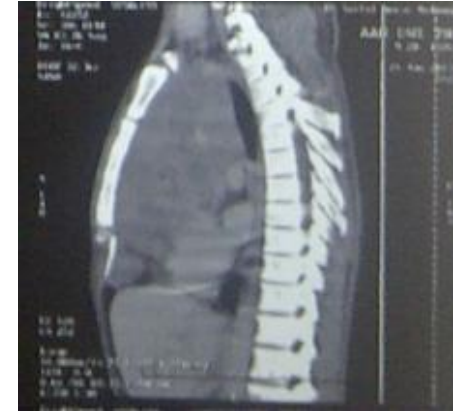

Sagital

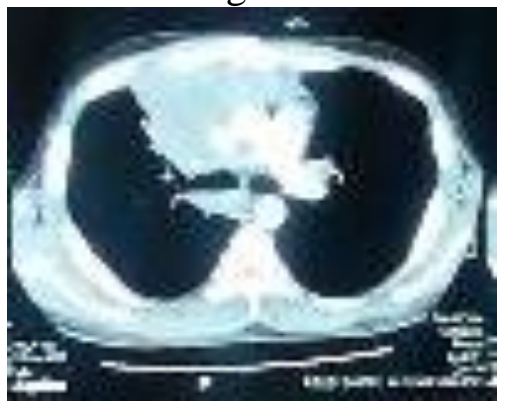

Sagital

Figure 4. Thoracic CT Scan with contrast showed anterior mediastinal mass attached to the thoracic wall and encased the vascular with multiple lymphadenopathy. (A) After 6th cycle of chemotherapy showed meediastinal mass with residual mass of thymoma with multiple mediastinal lymphadenopathy and bilateral lung nodules suspect metastatic process (B)

\section{Summary}

This patient was confirmed to have Well

\section{Differentiated Thymic Carcinoma}

Stadium IV (Thymoma B3) complicated with Vena Cava Superior Syndrome by clinical symptoms, thoracic CT-scan, and histopathology. The prognosis of this patient was poor because of the objective response of the chemotherapy was progressive, and the relapse case was higher.

\section{References}

1. Mariano C, Ionescu DN, Cheung WY, Ali RH, Laskin J, Evans K, Carolan $\mathrm{H}$, Murray N. Thymoma: a population-based study of the management and outcomes for the province of British Columbia. Journal of Thoracic Oncology. 2013 Jan 1;8(1):109-17.

2. Mohammadi F, Nadji SA, Karimi S, Mansoori SD, Sharifkashani S, Bahadori M. Detection of Epstein Barr Virus DNA in thymic epithelial tumor using nested PCR. Tanaffos. 2006 Jan 1;5(4):9-13.

3. Suster S, Moran CA. Thymoma classification: current status and future trends. American journal of clinical pathology. 2006 Apr 1;125(4):542-54. 
4. Roberts JR, Kaiser LR. Acquired lesion of the mediastinum: Benign and malignant disease. in Fishman A. Fishman's pulmonary disease and disorder. 4th ed. McGraw-Hill Co. 2008:1609.

5. Syahruddin E, Hudoyo A, Jusuf A, Pulmonologi D, Respirasi IK. Penatalaksanaan Tumor Mediastinum Ganas. Jurnal Respirologi Indonesia. 2009;29(4).

6. Müller-Hermelink HK, Engel P, Kuo TT, Ströbel P, Marx A, Harris NL, Travis WD, Brambilla E, Harris CC. Pathology \& genetics, tumours of the lung, pleura, thymus and heart. World Health Organization Classification of Tumors. Travis WD, Brambilla E, Müller-Hermelink HK, Harris CC, Eds. IARC Press, Lyon. 2004:146-7.

7. Xu C, Feng QF, Fan CC, Zhai YR, Chen YD, Zhang HX, Xiao ZF, Liang J, Chen DF, Zhou ZM, Wang LH. Patterns and predictors of recurrence after radical resection of thymoma. Radiotherapy and Oncology. 2015 Apr 1;115(1):30-4.

8. Wulandari L, Permatasari A. Case report : Management of Thymic Carcinoma Patients with Myasthenia Gravis. Jurnal Respirologi Indonesia. 2013. Vol 33; No. 1. pp 57-65 